\title{
Alterations in diurnal rhythmicity in patients treated for nonfunctioning pituitary macroadenoma: a controlled study and literature review
}

\author{
S D Joustra ${ }^{1}$, R D Thijss,3, R van den Berg ${ }^{1}$, M van Dijk ${ }^{1}$, A M Pereira', \\ G J Lammers ${ }^{2,3}$, E J W van Someren ${ }^{4,5}$, J A Romijn' ${ }^{1}$ and N R Biermasz' \\ ${ }^{1}$ Center for Endocrine Tumors Leiden, Department of Endocrinology and Metabolism and \\ ${ }^{2}$ Department of Neurology, Leiden University Medical Center, Albinusdreef 2, 2333ZA Leiden, The Netherlands, \\ ${ }^{3}$ Stichting Epilepsie Instellingen Nederland (SEIN), Achterweg 5, 2103SW Heemstede, The Netherlands, \\ ${ }^{4}$ Department of Sleep and Cognition, Netherlands Institute for Neuroscience, Meibergdreef 47, 1105BA \\ Amsterdam, The Netherlands and ${ }^{5} \mathrm{Neuroscience} \mathrm{Campus} \mathrm{Amsterdam,} \mathrm{Departments} \mathrm{of} \mathrm{Integrative} \mathrm{Neurophysiology}$ \\ and Medical Psychology, VU University and Medical Center, De Boelelaan 1117, 1081HZ Amsterdam, \\ The Netherlands
}

\author{
Correspondence \\ should be addressed \\ to S D Joustra \\ Email \\ SDJoustra@lumc.nl
}

\begin{abstract}
Objective: Patients treated for nonfunctioning pituitary macroadenomas (NFMAs) have fatigue and alterations in sleep characteristics and sleep-wake rhythmicity frequently. As NFMAs often compress the optic chiasm, these complaints might be related to dysfunction of the adjacent suprachiasmatic nucleus $(\mathrm{SCN})$. We aimed to explore whether indirect indices of SCN functioning are altered in the long term after surgery for NFMAs.

Methods: We studied 17 NFMA patients in long-term remission after transsphenoidal surgery, receiving adequate and stable hormone replacement for hypopituitarism, and 17 control subjects matched for age, gender, and BMI. Indirect indices of SCN function were assessed from 24-h ambulatory recordings of skin and core body temperatures, blood pressure, and salivary melatonin levels. Altered melatonin secretion was defined as an absence of evening rise, considerable irregularity, or daytime values $>3 \mathrm{pg} / \mathrm{ml}$. We additionally studied eight patients treated for craniopharyngioma.

Results: Distal-proximal skin temperature gradient did not differ between NFMAs and control subjects, but proximal skin temperature was decreased during daytime $(P=0.006)$. Core body temperature and non-dipping of blood pressure did not differ, whereas melatonin secretion was often altered in NFMAs (OR 5.3, 95\% Cl 0.9-30.6). One or more abnormal parameters ( $\geq 2.0$ SDS of control subjects) were observed during nighttime in 12 NFMA patients and during daytime in seven NFMA patients. Similar patterns were observed in craniopharyngioma patients.

Conclusion: Heterogeneous patterns of altered diurnal rhythmicity in skin temperature and melatonin secretion parameters were observed in the majority of patients treated for NFMAs. On a group level, both NFMA and craniopharyngioma patients showed a lower daytime proximal skin temperature than control subjects, but other group averages were not significantly different. The observations suggest altered function of central (or peripheral) clock machinery, possibly by disturbed entrainment or damage of the hypothalamic SCN by the suprasellar macroadenoma or its treatment.
\end{abstract}




\section{Introduction}

Nonfunctioning pituitary macroadenomas (NFMAs) often cause pituitary insufficiency and visual impairments due to compression of the optic chiasm. In case of visual field defects, transsphenoidal surgery is the treatment of choice, resulting in the improvement of visual function in the majority of patients (1). Selected patients require treatment by postoperative radiotherapy (2).

We previously reported that patients treated for NFMAs by surgery suffer in the long term from impaired quality of life, increased daytime somnolence, fatigue, and sleeping difficulties (3). In addition, polysomnography showed a lower sleep efficiency and less rapid eye movement (REM) sleep, while actigraphy showed fragmentation of the sleep-wake rhythm and longer sleep duration (3).

It has been postulated that the complaints of fatigue and somnolence can, at least in part, be attributed to hypopituitarism, hormonal replacement therapy (4), and/or an apathy syndrome (5). An alternate hypothesis holds that these complaints result from dysfunction of the suprachiasmatic nucleus (SCN). The SCN consists of a small group of hypothalamic neurons located in direct proximity to the optic chiasm, controlling the sleep-wake cycle and coordinating this with circadian rhythms in other brain areas and other tissues (6). Indirect support for this line of thought has been provided by a recent study in which a history of a suprasellar tumor with permanent visual field defects (NFMA in one of five patients) was associated with a reduced arginine vasopressin immunoreactivity in post-mortem SCN tissue (7).

Our aim is to explore whether diurnal parameters reflecting $\mathrm{SCN}$ function are altered in the long term after surgery for NFMAs. We investigated a comprehensive set of indices of SCN function consisting of 24-h ambulatory recordings of blood pressure, skin and core body temperatures, and salivary melatonin levels. We compared the results with those of healthy control subjects matched for gender, age, and BMI. For illustrative purposes, we additionally examined a small number of patients treated for craniopharyngioma, as a model for usually more extensive damage, inter alia to the hypothalamus (8).

\section{Subjects and methods}

\section{Subjects}

Patients were selected from a database containing all patients consecutively treated by transsphenoidal surgery for NFMAs in our institution $(n=226)$, between 1960 and 2008. Inclusion criteria were stable and adequate substitution of pituitary insufficiencies for at least 6 months (see Supplementary Information File, see section on supplementary data given at the end of this article for definitions) and an age of 18-65 years. Patients using hypnotics or psychotropic medication were excluded, as were patients suffering from conditions that may alter circadian rhythmicity, i.e. sleep disorders, depression, hypertension, dyslipidemia, and diabetes mellitus. A total of 43 patients fulfilled the inclusion criteria, of whom 17 participated. The clinical characteristics (including age, gender, tumor extension, visual field defects, or adjuvant radiotherapy) of the participants did not differ from those who did not participate. Visual field defects were assessed by Goldmann perimetry and evaluated by an ophthalmologist, who was unaware of the outcomes of the study.

In this study 17 gender-, age-, and BMI-matched control subjects were recruited via advertisement in local newspapers, using the same inclusion and exclusion criteria except for pituitary pathology.

Additionally, we studied eight patients previously treated for craniopharyngioma by transsphenoidal surgery. Identical inclusion and exclusion criteria were used as for NFMAs, except that the presence of hypertension and dyslipidemia was allowed because these conditions are frequently present in craniopharyngioma patients. As the craniopharyngioma group size was small, unmatched to the control subjects, and with considerable comorbidity, these patients were studied for illustrative purposes, and the results will only be discussed concisely (for details, see Supplementary File).

\section{Methods}

Study design - In this exploratory study, we assessed diurnal rhythmicity in 17 NFMA patients and 17 control subjects, using 24-h recordings of blood pressure, skin temperature, core body temperature, and 36-h profiles of salivary melatonin level. Measurements were obtained at home to facilitate normal sleep, simultaneous with previously reported polysomnographic and actigraphic measurements (see Supplementary Fig. 1 for study schedule) (3).

In eight patients treated for craniopharyngioma, we studied skin and core body temperatures, subjective complaints by questionnaires, sleep characteristics by polysomnography, and sleep-wake rhythmicity by 
actigraphy (see Supplementary File for methods and results from polysomnography, actigraphy, and questionnaires).

The Medical Ethical Committee of the Leiden University Medical Center approved this study, and all subjects gave written informed consent.

Recordings of 24-h skin and core body temperatures $>$ Core body temperature was monitored for $\sim 24 \mathrm{~h}$ at $1 \mathrm{~min}$ intervals by an ingestible Capsule Sensor (Jonah, Mini Mitter Co, Bend, OR, USA), with an accuracy of $\pm 0.05{ }^{\circ} \mathrm{C}$ between 32 and $42{ }^{\circ} \mathrm{C}$, and sent to the wearable Vitalsense monitor (Respironics, Bend, OR, USA). To minimize the influence of food and drinks, subjects were instructed to maintain an intake diary and consume only the products of $36-38{ }^{\circ} \mathrm{C}$ during the first $8 \mathrm{~h}$.

Skin temperature was measured at 1 min intervals for $24 \mathrm{~h}$ using a wireless Thermochron iButton DS1921H (Maxim/Dallas Semiconductor Corp., San Jose, CA, USA), with a mean accuracy of $-0.09{ }^{\circ} \mathrm{C}$ and precision of $0.05^{\circ} \mathrm{C}$ (9) fixed to the skin using a Fixomul tape (Beiersdorf, Hamburg, Germany). An automated artifact rejection procedure as used by Lichtenbelt et al. (9) was applied to exclude extreme drops and rises in temperature. Distal skin temperature was defined as the average of the thenar eminence of both palms and the medial metatarsal area of the plantar side of both feet. Measurements at both infraclavicular areas, $1 \mathrm{~cm}$ supraumbilical, and the left mid-thigh on the rectus femoris muscle, were used to calculate the proximal skin temperature (10): $0.383 \times$ midthigh $+0.293 \times$ infraclavicular $+0.324 \times$ supraumbilical . The distal-proximal gradient represents thermoregulatory skin blood flow of the extremities (11). Data were analyzed separately for the day and night periods (diary times of being in or out of bed).

Melatonin sampling - Melatonin was measured in saliva, which is a reliable index of serum melatonin level (12). Saliva was collected using Salivettes (Sarstedt, Nümbrecht, Germany) on two subsequent evenings (at 3, 2, and $1 \mathrm{~h}$ before and at habitual bedtime, and upon waking up spontaneously at night) and on the day in between (at awakening, 1 and $2 \mathrm{~h}$ after awakening, noon, and 3 p.m.) (13).

Patients were instructed to remain seated for $10 \mathrm{~min}$ before sampling to minimize the influence of postural changes (14), avoid eating or drinking for 30 min before sampling and report mucosal wounds (15). From $4 \mathrm{~h}$ before bedtime, until habitual bedtime, subjects were instructed to remain in dim light, e.g. by dimming light such that reading is just possible, closing the curtains, not sitting close to a lamp, not using a computer, and staying at least $3 \mathrm{~m}$ away from a television. During the entire collection period, subjects were not allowed to consume food dyes, chocolate, or banana (tryptophan increases melatonin production (16)), and alcohol, caffeine, or nonsteroidal anti-inflammatory drugs (which decrease melatonin levels $(17,18,19))$.

Samples were kept in the dark at $4{ }^{\circ} \mathrm{C}$ until the end of assessment, and then stored at $-20^{\circ} \mathrm{C}$ until analysis. Samples were centrifuged at $1800 \mathrm{~g}$ for $15 \mathrm{~min}$ and aliquots of $400 \mu \mathrm{l}$ were added to RIA kit tubes (RK-DSM; Bühlmann Laboratories AG, Schönenbuch, Switzerland). The detection limit was $0.3 \mathrm{pg} / \mathrm{ml}$ and the intra-assay and inter-assay precisions were 7.9 and $11.7 \%$ respectively.

Melatonin data were fitted to a skewed baseline cosine function (SBCF, see 'Statistical analysis' section) (13). Altered melatonin secretion was defined as an absence of evening rise, daytime values $>3 \mathrm{pg} / \mathrm{ml}$, or severe irregularity in melatonin secretion, as indicated by non-fitting of the SBCF. Outliers were defined as values that severely deviated from the prior and following sample and that prevented adequate SBCF fitting.

Measurement of 24-h blood pressure During $24 \mathrm{~h}$, using a Mobil-O-Graph v.12 (Industrielle Entwicklung Medizin (I.E.M.) technik GmbH, Stolberg, Germany) oscillometric blood pressure measurements were performed every $10 \mathrm{~min}$ (day) or $30 \mathrm{~min}$ (night) with an accuracy of $\pm 3 \mathrm{mmHg}$. Data were analyzed using Hypertension Management V6.02.040 (I.E.M. GmbH). Non-dipping of mean arterial pressure (MAP) in the evening was defined as $\mathrm{MAP}_{\text {night/day }}<10 \%(20)$.

Patterns of alterations in diurnal parameters $>$ To evaluate the distribution of alterations in all diurnal parameters within the patient cohort, and to identify patterns of altered parameters, $Z$-scores were calculated for individual patients, based on the control subjects' average and s.D. Altered diurnal parameters were defined as those deviating by more than 2.0 SDS and are separated for nighttime; i.e. low distal-proximal gradient, a delayed trough time or decreased trough depth in nighttime core body temperature, no melatonin rise, or non-dipping of blood pressure, and daytime, i.e. increased distal-proximal gradient, increased core body temperature, or increased melatonin values. Results were compared with the $Z$-scores from polysomnography and actigraphy, which were reported previously (3). 


\section{Statistical analysis}

The skewed baseline cosine function (SBCF) (13) was used to fit the melatonin data too. This function parsimoniously quantifies the typical fixed low level during daytime and allows for skewness of the nocturnal peak, i.e. differences in the steepness of the rising and falling limb of the melatonin peak:

$$
\begin{aligned}
Y(x)= & b+\frac{H}{2(1-c)}(\cos (x-\phi+v \cos (x-\phi))-c \\
& +|\cos (x-\phi+v \cos (x-\phi))-c|)
\end{aligned}
$$

$Y$ represents the predicted value of melatonin at time $x$ (in radians, $0-2 \times \pi)$. The five parameters are directly proportional to the baseline level ( $b$, average level during daytime), the relative peak height ( $H$, peak level), the width ( $c$, duration of peak), the phase ( $\varphi$, in radians), and the skewness $(v)$ of the peak. The best fit was calculated using the Levenberg-Marquardt algorithm for nonlinear curve fitting included in using SPSS for Windows, version 20.0 (SPSS, Inc.). The onset time of the rise from baseline was calculated as $(\varphi-0.5 c) /(2 \pi)$, the peak time as the time of the highest SBCF value, the absolute peak as $b+H$, and the skewness of the evening upslope as $H /$ (top time-starting time of rise). Patients were instructed to maintain their habitual bedtime, and melatonin samples were collected relative to that bedtime. To correct for the influence of differences in habitual bedtime on the individual timing of melatonin secretion, the data of all subjects were aligned at the individual bedtimes.

Unpaired Student's $t$-tests, Pearson's $\chi^{2}$-test or Fisher's exact test, and Pearson's or Spearman's correlation were used when appropriate. Differences were considered statistically significant at $P<0.05$.

\section{Results}

\section{Clinical characteristics}

All 17 NFMA patients (age 26-65 years, eight females) had been treated by transsphenoidal surgery for suprasellar extension and were in remission, considered as absence of or stable residual adenoma, for a median of 8 years (range 1-18 years) (Table 1 ). The tumor size according to Hardy's classification was invasive (III/IV) in six patients, extending into the suprasellar cistern in one, into the recesses of the third ventricle in 17 patients, and in the parasellar region in five patients; 14 patients (82\%) presented with visual field defects that had resolved almost completely postoperatively; and five patients received postoperative radiotherapy for remnants or postoperative tumor growth. At inclusion, 29\% had adrenocorticotropic hormone (ACTH) deficiency, 65\% growth hormone (GH) deficiency (GHD), 59\% thyroid-stimulating hormone deficiency, and 35\% luteinizing hormone/follicle-stimulating hormone deficiency (four males and two females, the other females were postmenopausal). All patients received adequate stable replacement therapy for pituitary deficiencies except for GHD, which was untreated in three out of 11 GHD patients due to contraindications or patient's preference. As per inclusion criterion of the NFMAs group, all patients were otherwise healthy. The 17 control subjects did not differ from the NFMA patients in gender, age, or BMI.

\section{Diurnal variation in skin and core body temperatures}

Distal-proximal gradient did not differ significantly between NFMA patients and control subjects, but the proximal skin temperature during daytime was decreased in NFMA patients (mean difference $0.49{ }^{\circ} \mathrm{C}, 95 \%$ CI 0.15 $0.84^{\circ} \mathrm{C}, P=0.006$; Table 2 ). There were no significant group differences in the core body temperature or in any of the nighttime parameters. Within patients, lower proximal skin temperature during daytime correlated with more general fatigue (MFI-20 questionnaire; $r=-0.523$, $P=0.031$ ) and lower physical function (SF-36 questionnaire; $r=0.558, P=0.020$ ). In addition, a higher distalproximal gradient during daytime correlated with less physical fitness (MFI-20; $r=0.479, P=0.052$ and SF-36; $r=-0.560, P=0.020)$.

\section{Melatonin curves in saliva}

In three NFMA patients and eight control subjects, a distinct outlier was removed to fit the SBCF, and in seven NFMA patients (vs two control subjects), the two subsequent evening rises were so differently timed that only the first evening was used for fitting (Table 3).

Abnormal melatonin secretion was observed in seven NFMA patients vs two control subjects (OR 5.3, 95\% CI 0.9-30.6, $P=0.12$ ). Of these seven NFMA patients, the SBCF curve could not be fitted in five NFMA patients due to either an absence of evening rise $(n=4)$ or considerable irregularity $(n=1)$. In one of the four patients with an absent evening rise, nighttime melatonin production was observed in a $0400 \mathrm{~h}$ sample. In the other three, no night samples were collected. In control subjects, only two curves could not be adequately fitted, both due to 
Table 1 Clinical characteristics of patients with NFMA or CR, and healthy control subjects. Data represent $n$ (\%) or average \pm s.D., unless described otherwise.

\begin{tabular}{|c|c|c|c|}
\hline & NFMA $(n=17)$ & $\mathbf{C R}(n=8)$ & Control subjects $(n=17)$ \\
\hline No. of women & $8(47 \%)$ & $1(13 \%)$ & $6(35 \%)$ \\
\hline Age (years), median (range) & $54(26-65)$ & $50(31-62)$ & $52(30-63)$ \\
\hline BMI $\left(\mathrm{kg} / \mathrm{m}^{2}\right)$ & $25.1 \pm 2.5$ & $29.1 \pm 2.7^{*}$ & $27.1 \pm 3.8$ \\
\hline Waist circumference $(\mathrm{cm})$ & $100.6 \pm 12.9 *$ & $102.4 \pm 9.1$ * & $91.4 \pm 10$ \\
\hline Years after surgery, median (range) & $8(1-18)$ & $21(11-35)$ & \\
\hline Adjuvant radiotherapy & $5(29 \%)$ & $4(50 \%)$ & \\
\hline VFD at presentation & $14(82 \%)$ & $7(88 \%)$ & \\
\hline Any pituitary insufficiency & $15(88 \%)$ & $8(100 \%)$ & \\
\hline \multicolumn{4}{|l|}{ Sleep characteristics ${ }^{a}$} \\
\hline Total sleep time (min) & $433 \pm 98$ & $439 \pm 67$ & $455 \pm 66$ \\
\hline Sleep efficiency & $86.1 \pm 9.1 *$ & $87.7 \pm 4.4^{*}$ & $92.9 \pm 3.1$ \\
\hline$\%$ NREM 1 of TST & $19.9 \pm 10.2^{*}$ & $7.9 \pm 4.3$ & $9.5 \pm 4.4$ \\
\hline$\%$ NREM 2 of TST & $42.3 \pm 9.0$ & $38.1 \pm 10.0$ & $40.3 \pm 7.0$ \\
\hline$\%$ NREM 3 of TST & $19.8 \pm 9.3$ & $24.0 \pm 13.5$ & $24.6 \pm 5.1$ \\
\hline$\%$ REM of TST & $17.1 \pm 5.0 *$ & $18.5 \pm 4.7 *$ & $25.4 \pm 4.4$ \\
\hline$\%$ awake of sleep period & $13.7 \pm 9.1 *$ & $11.6 \pm 4.4^{*}$ & $6.6 \pm 3.1$ \\
\hline Apnea or hypopnea per hour & $5.7 \pm 7.5$ & $3.9 \pm 3.4$ & $7.0 \pm 6.0$ \\
\hline \multicolumn{4}{|l|}{ Sleep-wake rhythmicity ${ }^{\mathrm{b}}$} \\
\hline Average activity level & $35.6 \pm 4.3$ & $38.4 \pm 4.2$ & $38.4 \pm 4.3$ \\
\hline Interdaily stability & $0.75 \pm 0.10$ & $0.77 \pm 0.11$ & $0.78 \pm 0.10$ \\
\hline Intradaily variability & $0.44 \pm 0.10 *$ & $0.38 \pm 0.07$ & $0.34 \pm 0.07$ \\
\hline \multicolumn{4}{|l|}{ Subjective sleep qualityc } \\
\hline Berlin Questionnaire (high risk) & $5(29 \%) *$ & $4(50 \%)^{*}$ & $0(0 \%)$ \\
\hline Clinical symptom score & $3.71 \pm 2.0 *$ & $4.38 \pm 1.85^{*}$ & $1.47 \pm 1.4$ \\
\hline Epworth Sleepiness Scale & $6.53 \pm 5.8$ & $11.38 \pm 4.31 *$ & $4.82 \pm 3.2$ \\
\hline \multicolumn{4}{|l|}{ Quality of life $e^{c}$} \\
\hline HADS (total score) & $7.74 \pm 5.7$ & $6.38 \pm 4.6$ & $4.59 \pm 3.2$ \\
\hline SF-36 (physical function) & $85.58 \pm 18.8^{*}$ & $75.63 \pm 25.4 *$ & $97.06 \pm 3.1$ \\
\hline
\end{tabular}

VFD, visual field defects; CR, craniopharyngioma; HADS, Hospital Anxiety and Depression Scale; SF-36, Short Form-36. *Significantly different from control subjects at $P<0.05$.

${ }^{a}$ Assessed with polysomnography.

${ }^{\mathrm{b}}$ Assessed with actigraphy.

'See reference (3) for NFMA details and Supplementary Information File for CR details.

irregularity of the evening rise. However, nighttime melatonin production was observed in both of them. Furthermore, in three NFMA patients (vs zero control subjects), increased mid-daytime melatonin values were observed (4.1, 4.3, and $67.7 \mathrm{pg} / \mathrm{ml}$ respectively), indicating incomplete suppression of melatonin production during daytime. Within patients, altered melatonin secretion correlated with more sleep disturbances (PSQI questionnaire; $r=0.644, P<0.01)$ and lower physical function (SF-36 questionnaire; $r=-0.486, P=0.048$ ). SBCF parameters of fitted curves did not differ significantly between patients and control subjects, nor did habitual bedtimes (2326 h $\pm 35 \mathrm{~min}$ vs $2340 \mathrm{~h} \pm 39 \mathrm{~min}, P=0.279)$.

\section{Diurnal variation in blood pressure}

No group differences in the physiological evening drop or morning rise in blood pressure were observed between
NFMA patients and control subjects (Table 4). Daytime systolic blood pressure was mildly increased in NFMA patients (mean difference $8.2 \mathrm{mmHg}$, 95\% CI 0.3-16.2 mmHg, $P=0.042$ ).

\section{Patterns of alterations in diurnal parameters}

Diurnal parameters during the night $>$ Out of 17 NFMA patients, 12 (71\%) showed at least one of the five possible abnormal parameters during the night (Fig. 1), i.e. a low distal-proximal gradient $(n=1)$, a delayed trough time $(n=2)$, or decreased trough depth $(n=3)$ in nighttime core body temperature, no melatonin rise $(n=4)$, or non-dipping of blood pressure $(n=2)$.

The two most illustrative cases showed a nighttime distal-proximal gradient of -6.4 and -1.6 SDS. In these cases, polysomnography revealed an increased sleep period $(+2.4$ and +1.4 SDS $)$, decreased percentages 
Table 2 Skin and core body temperatures in patients with NFMA or CR and healthy control subjects. Data represent average \pm s.D. $\left({ }^{\circ} \mathrm{C}\right)$.

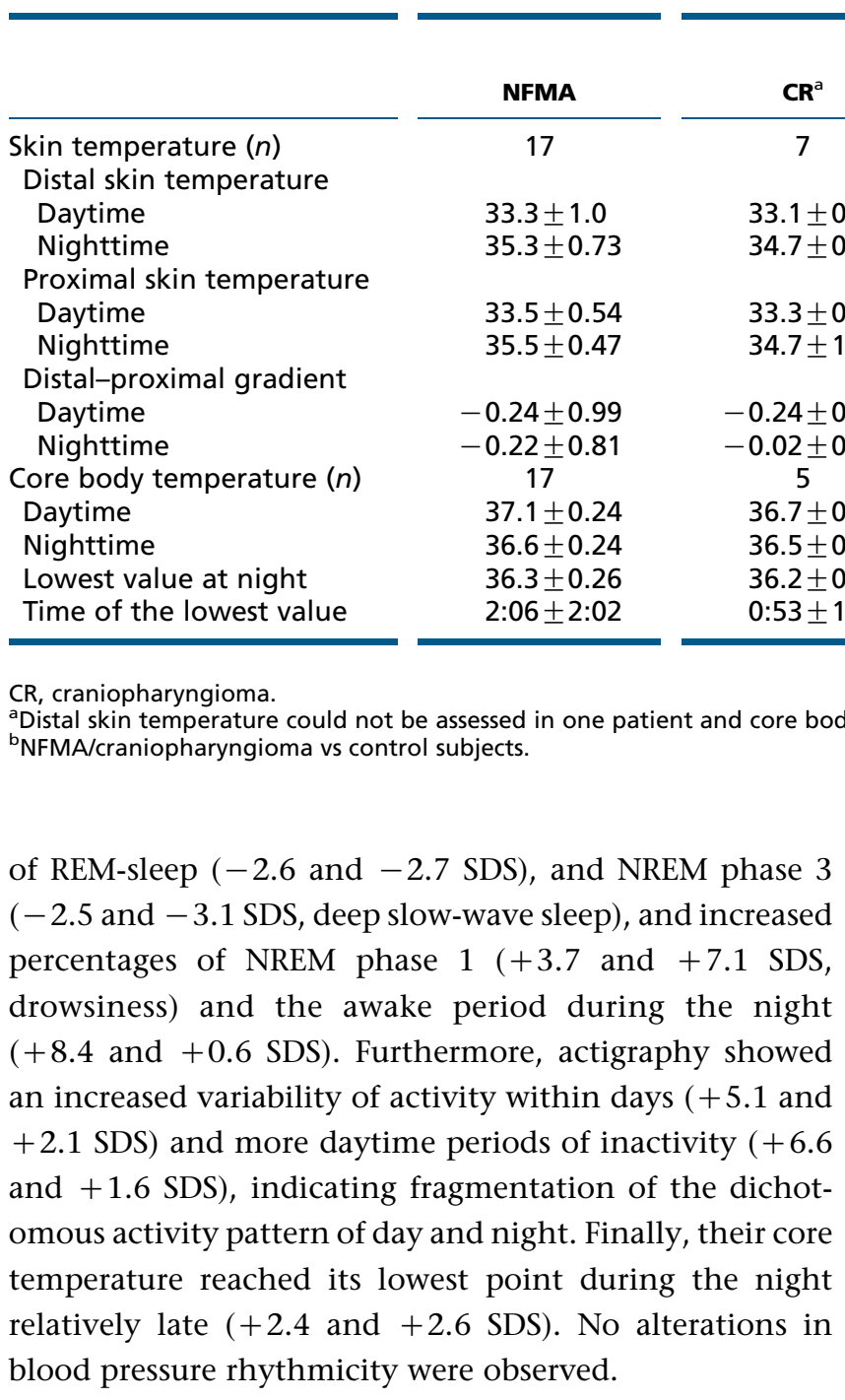

Diurnal parameters during daytime $>$ Out of 17 NFMA patients, seven (41\%) showed at least one of the three possible abnormal parameters during daytime, i.e. either an increased distal-proximal gradient $(n=4)$, increased core body temperature $(n=2)$, or increased melatonin values $(n=4)$. Furthermore, lower daytime proximal skin temperatures in NFMA patients were associated with increased daytime melatonin values $(r=-0.527$, $P=0.036)$, indicating that this feature may be linked to altered SCN function.

The four most illustrative patients showed high values of melatonin at 3 p.m. $(+5.7,+6.7,+15.4$, and +16.7 SDS $)$

Table 3 Melatonin SBCF in NFMA patients and healthy control subjects. Data are expressed as average \pm s.D. or $n$ (\%).

\begin{tabular}{lc}
\hline & NFMA $(n=17)$ \\
\cline { 1 - 2 } SBCF fitted & $12(71 \%)$ \\
Baseline level $(\mathrm{pg} / \mathrm{ml})$ & $0.49 \pm 0.31$ \\
Top height $(\mathrm{pg} / \mathrm{ml})$ & $12.49 \pm 7.22$ \\
Acrophase (radian) & $0.83 \pm 0.29$ \\
Width (radian) & $-0.12 \pm 0.16$ \\
Skewness (radian) & $0.13 \pm 0.28$ \\
Strength of fit $\left(R^{2}\right)$ & $0.97 \pm 0.03$ \\
Time of start rise & $-2 \mathrm{~h} 19 \mathrm{~min} \pm 1 \mathrm{~h} 13 \mathrm{~min}$ \\
Slope (pg/ml per $\mathrm{h})$ & $2.18 \pm 1.60$ \\
Top time $^{\mathrm{a}}$ & $+3 \mathrm{~h} 41 \mathrm{~min} \pm 1 \mathrm{~h} 33 \mathrm{~min}$ \\
Abnormal profile $^{\mathrm{b}}$ & $7(41 \%)$ \\
\hline
\end{tabular}

\begin{tabular}{ccc}
\hline Control subjects $(n=17)$ & & P value \\
\hline $15(88 \%)$ & & 0.398 \\
$0.53 \pm 0.28$ & & 0.796 \\
$12.43 \pm 6.39$ & 0.983 \\
$0.65 \pm 0.32$ & 0.150 \\
$-0.01 \pm 0.20$ & 0.148 \\
$0.02 \pm 0.29$ & 0.310 \\
$0.96 \pm 0.03$ & 0.204 \\
$-2 \mathrm{~h} 35 \min \pm 1 \mathrm{~h} 12 \mathrm{~min}$ & 0.578 \\
$2.03 \pm 1.05$ & 0.773 \\
$+3 \mathrm{~h} 23 \min \pm 1 \mathrm{~h} 1 \mathrm{~min}$ & 0.558 \\
$2(12 \%)$ & 0.118
\end{tabular}

SBCF, skewed baseline cosine function

${ }^{a}$ Relative to the person's habitual bedtime (mean bedtimes: $2326 \mathrm{~h} \pm 35 \mathrm{~min}$ for NFMA and $2340 \mathrm{~h} \pm 39 \mathrm{~min}$ for control subjects).

b Defined as either non-fitting of the SBCF (five patients vs two control subjects) or daytime values $>3 \mathrm{pg} / \mathrm{ml}$ (three patients vs zero control subjects). 
Table 4 24-h Blood pressure in NFMA patients and healthy control subjects. Data are expressed as average \pm s.D. $(\mathrm{mmHg})$.

\begin{tabular}{|c|c|c|c|}
\hline & $\begin{array}{l}\text { NFMA } \\
(n=17)\end{array}$ & $\begin{array}{c}\text { Control } \\
\text { subjects }(n=17)\end{array}$ & $P$ value \\
\hline \multicolumn{4}{|l|}{ Daytime } \\
\hline Systolic & $131.7 \pm 10.6$ & $123.5 \pm 12.1$ & 0.042 \\
\hline Diastolic & $80.6 \pm 9.6$ & $78.9 \pm 9.5$ & 0.619 \\
\hline \multicolumn{4}{|l|}{ Nighttime } \\
\hline Systolic & $111.8 \pm 10.9$ & $106.1 \pm 12.1$ & 0.162 \\
\hline Diastolic & $67.7 \pm 8.5$ & $65.6 \pm 9.9$ & 0.509 \\
\hline \multicolumn{4}{|l|}{ Dipping } \\
\hline$\triangle$ MAP day-night & $15.2 \pm 5.7$ & $14.7 \pm 7.3$ & 0.808 \\
\hline Non-dipping ${ }^{a}$ & $2(13 \%)$ & $1(6 \%)$ & 1.000 \\
\hline \multicolumn{4}{|l|}{ Morning rise } \\
\hline Start time & $4: 58 \pm 1: 46$ & $4: 44 \pm 1: 47$ & 0.718 \\
\hline End time & $10: 09 \pm 1: 27$ & $10: 11 \pm 1: 40$ & 0.946 \\
\hline Time of max. rise & $7: 36 \pm 1: 16$ & $7: 28 \pm 1: 15$ & 0.775 \\
\hline $\begin{array}{l}\text { Maximum slope of } \\
\text { rise }(\mathrm{mmHg} / \mathrm{h})\end{array}$ & $7.14 \pm 2.80$ & $7.71 \pm 3.64$ & 0.632 \\
\hline
\end{tabular}

MAP, mean arterial pressure.

a Less than $10 \%$ decrease in MAP, $n(\%)$.

and increased daytime distal-proximal skin temperature gradient $(+1.6,+2.2,+2.8$, and +1.9 SDS $)$. A tendency toward a higher variability of activity within days $(+0.9$, +2.4 , +0.4 , and +3.9 SDS) and more daytime inactive periods $(+1.4,-0.8,+2.4$, and +2.7 SDS $)$ was also observed by actigraphy. Blood pressure rhythmicity was not altered in any of them.

Inadequate diurnal parameters either during day- or nighttime did not correlate with clinical characteristics (including visual field defects) or treatment.

\section{Craniopharyngioma patients}

Skin and core body temperatures $\downarrow$ In accordance with the observations in NFMA patients, proximal skin temperature was decreased in craniopharyngioma patients when compared with control subjects (Supplementary File). In addition, the nighttime proximal skin temperature was also decreased, and the distal-proximal skin temperature gradient during the night was higher than control subjects.

Polysomnography and actigraphy - As reported in NFMA patients (3), craniopharyngioma patients had increased percentages of awakening at night, lower sleep efficiency, and decreased percentages of REM sleep, when compared with control subjects. Furthermore, a slight trend toward increased fragmentation of day-night rhythmicity was observed by actigraphy.
Questionnaires - Compared with control subjects, craniopharyngioma patients reported profoundly decreased quality of life, increased fatigue and sleepiness, and decreased sleep quality in questionnaires.

\section{Discussion}

The aim of this study was to explore whether indirect indices of diurnal SCN functioning were altered in the long term after surgery for NFMAs. The main results were decreased proximal skin temperature during daytime, and altered patterns of melatonin secretion in $41 \%$ of patients. We did not observe significant group differences in core body temperature and blood pressure rhythmicity.

Although increasing attention has been focused on hypothalamic function in patients with pituitary disease (Table 5), research on diurnal rhythmic parameters is complex. The SCN rostrally projects into the adjacent preoptic area of the anterior hypothalamus that serves a central and direct role in the thermoregulation (21). The well-established 24-h pattern in both core and skin temperature, especially the relative warming of distal skin (expressed as the distal-proximal gradient), is closely related to sleep initiation (22). In addition to these direct effects of the SCN on thermoregulation, distal-proximal gradient is indirectly influenced via the effects of melatonin, secretion of which from the pineal gland is regulated by the SCN (23). In addition to the direct

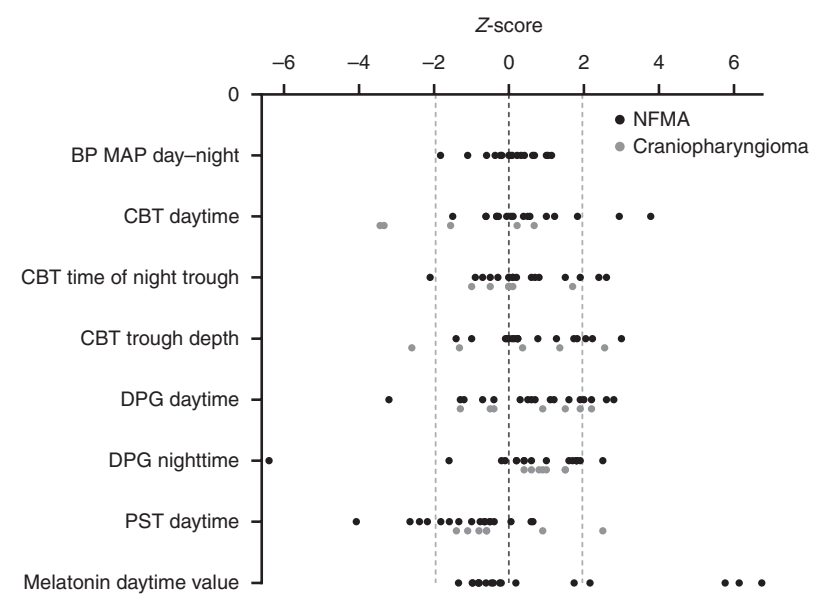

Figure 1

Individual Z-scores of nonfunctioning pituitary macroadenomas (NFMAs) and craniopharyngioma patients. BP MAP, mean arterial blood pressure; CBT, core body temperature; DPG, distal-proximal skin temperature gradient; PST, proximal skin temperature. 

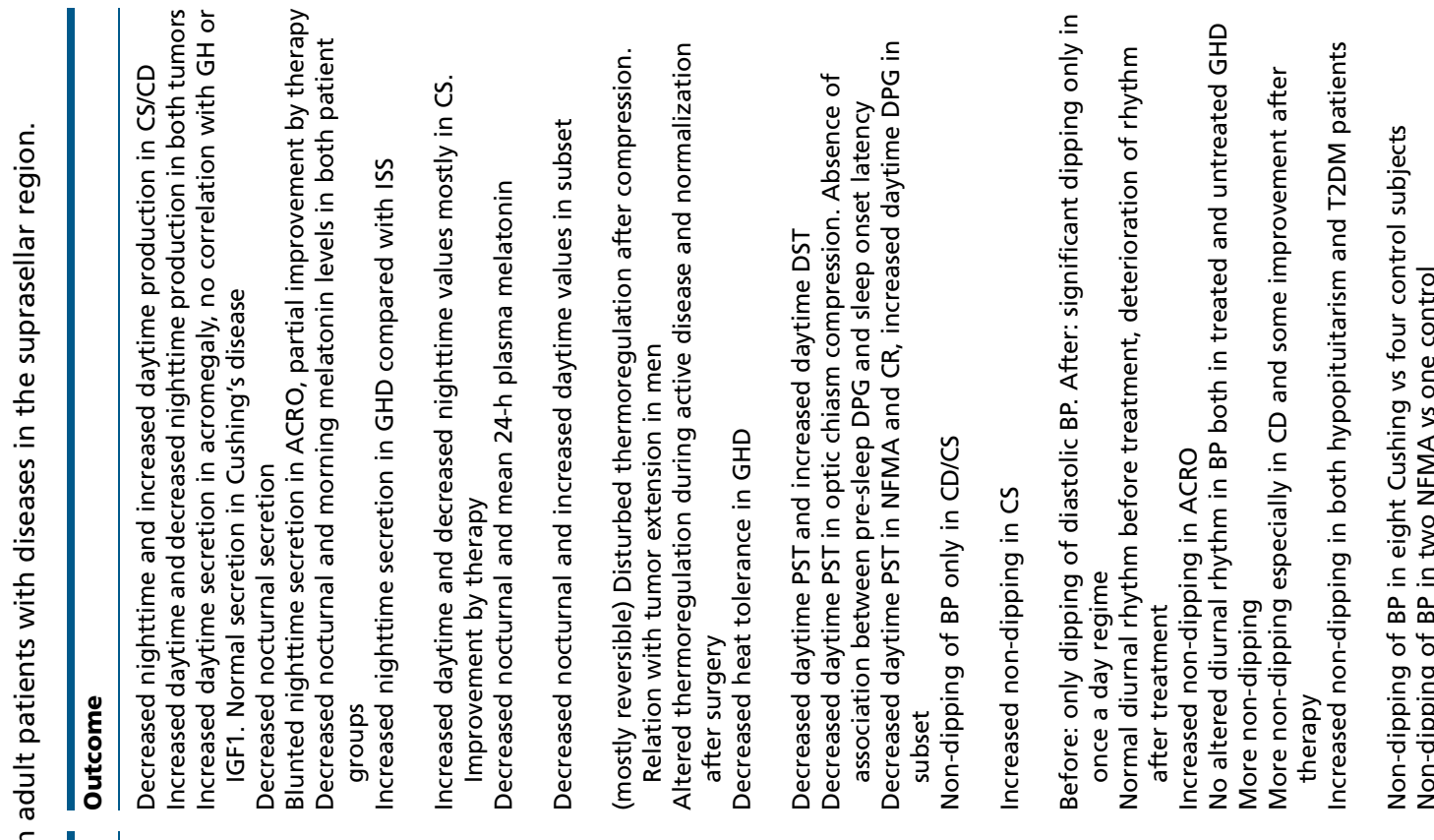

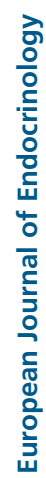

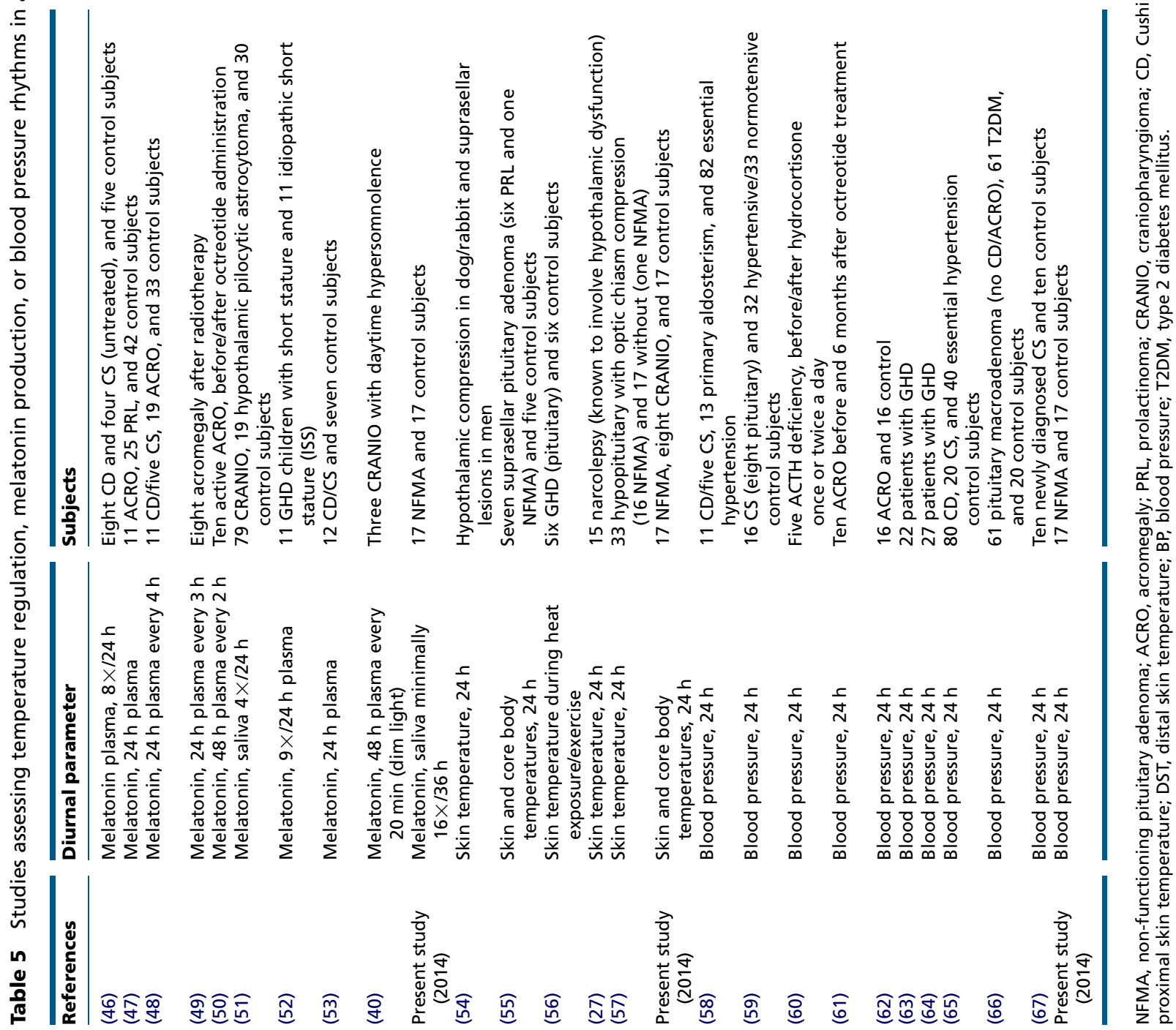


soporific effect on the CNS (23), melatonin strongly promotes distal skin warming through selective opening of arteriovenous anastomoses in the skin (24). Although disruptions of temperature rhythmicity have been described in humans following a hypothalamic lesion $(25,26)$, diurnal regulation of skin temperature has never been studied in a cohort of patients with NFMAs. However, our results are in general accordance with findings in other suprasellar or hypothalamic diseases (Table 5). The decrease in proximal skin temperature that we observed might explain the alterations in sleep quality and daytime wakefulness reported previously (3), as decreased proximal skin temperature is related to an increased sleep latency in both narcoleptics and healthy persons $(27,28)$, and to sleep depth (29).

In addition, altered melatonin secretion might explain the alterations, as 41\% of NFMA patients either had high daytime values, no evening rise, or severe irregularity of melatonin secretion. By contrast, only two control subjects had irregularity of the evening rise. Melatonin has never been studied in NFMA patients, but the results are in general accordance with those in other pituitary tumors (Table 5).

Blood pressure follows a distinct diurnal pattern (30). Multisynaptic pathways connect the SCN to the heart (31) and the variations in blood pressure are abolished after a SCN lesion in rodents (32). In addition, both melatonin (33) and skin temperature (34) modulate blood pressure rhythmicity. On the other hand, some have proposed that the effects of sleep and activity patterns $(35,36)$, and sleep deprivation $(37,38)$, influence variability in blood pressure more than the direct effects of circadian pacemakers. This, in addition to the exclusion of patients with hypertension, might explain as to why we did not observe differences in the evening drop or morning rise. Although diurnal patterns of blood pressure have not been studied in NFMA patients before, non-dipping has been inconsistently observed in patients with Cushing's syndrome, acromegaly, and GHD (Table 5).

Parameters of hypothalamic diurnal rhythmicity were heterogeneously affected among NFMA patients. From a pathophysiological point of view, it is conceivable that variable damage of SCN and adjacent nuclei may be present in NFMAs, regarding the highly variable clinical presentations and an unknown suprasellar growth velocity before presentation. The heterogeneous patterns of alterations might therefore be explained by the great variety of areas within the SCN and its efferent projections that can be damaged by a pituitary macroadenoma, as illustrated by studies attempting to specifically ablate SCN in rodents (39). In our cohort of NFMA patients, various patterns of altered night parameters were observed in $71 \%$ and of daytime parameters in $41 \%$ of the patients. The results suggest irreversible damage to the $\mathrm{SCN}$ in patients in long-term remission after being treated successfully for NFMAs. This suggestion is strengthened by a similar trend of an altered diurnal rhythmicity that we observed in craniopharyngioma patients, who are known to often exhibit hypothalamic dysfunction $(8,40)$. In addition, the hypothesis is supported by our previous observation of altered sleep characteristics and sleep-wake rhythmicity in long-term postoperative follow-up for NFMAs (3). Other reports include decreased sleep duration after compression of the optic chiasm of miscellaneous origin (41) and increased adult sleep duration after cranial radiation therapy in childhood (42).

Alternatively, the decreased sleep efficiency and altered sleep stage distribution that we observed in our previous study (3), or intrinsic imperfections of hormone replacement therapy might cause or contribute to altered entrainment of central and peripheral clocks (43), which in turn could influence diurnal rhythms of melatonin and temperature. However, this does not explain as to why patients with a history of NFMAs show disturbed sleep in the first place, even in the absence of hypopituitarism. Therefore, although the disturbed rhythmicity might also cause altered entrainment of clock genes, we believe that these macroadenoma cause damage in the hypothalamic region above the chiasm, resulting in the altered function of (and most importantly) the SCN inter alia.

If our hypothesis is correct, NFMA patients with complaints of insomnia, daytime fatigue, or daytime somnolence might benefit from treatment with melatonin, especially when the evening rise is absent. Additionally, behavioral therapy might improve daytime sleepiness, e.g. through regularization of sleep patterns by maintaining a regular schedule for going to bed and waking up, and engaging in stimulating activities and light exposure immediately after waking up (44).

Several limitations of this study need to be addressed. Data were collected at home, providing a patient-friendly assessment of natural sleep resulting in reliable polysomnographic results and an acceptable group size. However, the disadvantage of this method was that melatonin could only be measured at night if patients were awake and environmental temperatures could not be standardized. The latter might have affected the distal skin temperature. Although we assessed a group of patients without comorbidity other than pituitary disease, we cannot exclude that the (variable) degree of 
hypopituitarism and its replacement influenced the results. However, this is an innate drawback of all human studies on pituitary disease. For example, oral contraceptives raise the core body temperature in young healthy women (45). In agreement, we found an increased core body temperature (+3.8 SDS at day and +2.9 SDS at night) in two premenopausal NFMA patients using estrogen/progesterone replacement. However, exclusion of these patients did not alter the results.

Finally, as a consequence of the strict exclusion of patients with comorbidity, our cohort represents the healthiest subgroup of patients. It is conceivable that in patients with more comorbidity, the macroadenoma was more damaging, possibly with a higher likelihood of hypothalamic damage. This selection bias, although providing us with the most reliable outcome measurements, might have limited our probability of observing hypothalamic dysfunction.

In conclusion, heterogeneous patterns of altered diurnal rhythmicity in skin temperature and melatonin secretion parameters were observed in the majority of patients treated for NFMAs. At a group level, both NFMA and craniopharyngioma patients showed lower daytime proximal skin temperature than control subjects, but other group averages were not significantly different. The observed alterations might be caused by disturbed entrainment of central and peripheral clock machinery or damage of the hypothalamic SCN either caused by the suprasellar macroadenoma, or transsphenoidal surgery. Diurnal and autonomic parameters need to be further studied in larger cohorts of NFMA patients, under controlled and/or provoked circumstances.

Supplementary data

This is linked to the online version of the paper at http://dx.doi.org/10.1530/ EJE-14-0172.

\section{Declaration of interest}

The authors declare that there is no conflict of interest that could be perceived as prejudicing the impartiality of the research reported.

Funding

N R Biermasz was supported by The Netherlands Organisation for Health Research and Development (Clinical Fellows 90700195, Veni 91613125).

\section{Acknowledgements}

The investigators thank Dr M C M Gordijn (University of Groningen, The Netherlands) for the melatonin assays and Prof. Dr J G van Dijk for conceptualizing the study. Finally, we thank the efforts of the neurophysiology technologists of the Department of Neurology and patients and control subjects who participated in this study.

\section{References}

1 Dekkers OM, de Keizer RJ, Roelfsema F, Vd Klaauw AA, Honkoop PJ, van Dulken H, Smit JW, Romijn JA \& Pereira AM. Progressive improvement of impaired visual acuity during the first year after transsphenoidal surgery for non-functioning pituitary macroadenoma. Pituitary 2007 10 61-65. (doi:10.1007/s11102-007-0007-0)

2 Park P, Chandler WF, Barkan AL, Orrego JJ, Cowan JA, Griffith KA \& Tsien $\mathrm{C}$. The role of radiation therapy after surgical resection of nonfunctional pituitary macroadenomas. Neurosurgery 200455 100-106. (doi:10.1227/01.NEU.0000126885.71242.D7)

3 Biermasz NR, Joustra SD, Donga E, Pereira AM, van Duinen N, van Dijk M, van der Klaauw AA, Corssmit EP, Lammers GJ, van Kralingen KW et al. Patients previously treated for nonfunctioning pituitary macroadenomas have disturbed sleep characteristics, circadian movement rhythm, and subjective sleep quality. Journal of Clinical Endocrinology and Metabolism 201196 1524-1532. (doi:10.1210/ jc.2010-2742)

4 Romijn JA, Smit JW \& Lamberts SW. Intrinsic imperfections of endocrine replacement therapy. European Journal of Endocrinology 2003 149 91-97. (doi:10.1530/eje.0.1490091)

5 Weitzner MA, Kanfer S \& Booth-Jones M. Apathy and pituitary disease: it has nothing to do with depression. Journal of Neuropsychiatry and Clinical Neurosciences 200517 159-166. (doi:10.1176/appi.neuropsych. 17.2.159)

6 Moore RY. Suprachiasmatic nucleus in sleep-wake regulation. Sleep Medicine 20078 (Suppl 3) 27-33. (doi:10.1016/j.sleep.2007.10.003)

7 Borgers AJ, Fliers E, Siljee JE, Swaab DF, Van Someren EJ, Bisschop PH \& Alkemade A. Arginine vasopressin immunoreactivity is decreased in the hypothalamic suprachiasmatic nucleus of subjects with suprasellar tumors. Brain Pathology 201323 440-444. (doi:10.1111/bpa.12016)

8 Ullrich NJ, Scott RM \& Pomeroy SL. Craniopharyngioma therapy: longterm effects on hypothalamic function. Neurologist 200511 55-60. (doi:10.1097/01.nrl.0000149971.27684.d4)

9 van Marken Lichtenbelt WD, Daanen HA, Wouters L, Fronczek R, Raymann RJ, Severens NM \& Van Someren EJ. Evaluation of wireless determination of skin temperature using iButtons. Physiology \& Behavior 200688 489-497. (doi:10.1016/j.physbeh.2006.04.026)

10 Krauchi K, Cajochen C, Mori D, Graw P \& Wirz-Justice A. Early evening melatonin and S-20098 advance circadian phase and nocturnal regulation of core body temperature. American Journal of Physiology 1997272 R1178-R1188.

11 Rubinstein EH \& Sessler DI. Skin-surface temperature gradients correlate with fingertip blood flow in humans. Anesthesiology 199073 541-545. (doi:10.1097/00000542-199009000-00027)

12 Voultsios A, Kennaway DJ \& Dawson D. Salivary melatonin as a circadian phase marker: validation and comparison to plasma melatonin. Journal of Biological Rhythms 199712 457-466.

13 Van Someren EJ \& Nagtegaal E. Improving melatonin circadian phase estimates. Sleep Medicine 20078 590-601. (doi:10.1016/j.sleep. 2007.03.012)

14 Deacon S \& Arendt J. Posture influences melatonin concentrations in plasma and saliva in humans. Neuroscience Letters 1994167 191-194. (doi:10.1016/0304-3940(94)91059-6)

15 Benloucif S, Burgess HJ, Klerman EB, Lewy AJ, Middleton B, Murphy PJ, Parry BL \& Revell VL. Measuring melatonin in humans. Journal of Clinical Sleep Medicine 20084 66-69.

16 Wurtman RJ, Larin F, Axelrod J, Shein HM \& Rosasco K. Formation of melatonin and 5-hydroxyindole acetic acid from 14C-tryptophan by 
rat pineal glands in organ culture. Nature 1968217 953-954. (doi:10. 1038/217953a0)

17 Wright KP Jr, Badia P, Myers BL, Plenzler SC \& Hakel M. Caffeine and light effects on nighttime melatonin and temperature levels in sleepdeprived humans. Brain Research $1997 \mathbf{7 4 7}$ 78-84. (doi:10.1016/S00068993(96)01268-1)

18 Ekman AC, Leppaluoto J, Huttunen P, Aranko K \& Vakkuri O. Ethanol inhibits melatonin secretion in healthy volunteers in a dose-dependent randomized double blind cross-over study. Journal of Clinical Endocrinology and Metabolism 199377 780-783.

19 Murphy PJ, Myers BL \& Badia P. Nonsteroidal anti-inflammatory drugs alter body temperature and suppress melatonin in humans. Physiology \& Behavior 199659 133-139. (doi:10.1016/0031-9384(95)02036-5)

20 Birkenhager AM \& van den Meiracker AH. Causes and consequences of a non-dipping blood pressure profile. Netherlands Journal of Medicine 200765 127-131.

21 Romanovsky AA. Thermoregulation: some concepts have changed. Functional architecture of the thermoregulatory system. American Journal of Physiology. Regulatory, Integrative and Comparative Physiology 2007292 R37-R46. (doi:10.1152/ajpregu.00668.2006)

22 Krauchi K. The thermophysiological cascade leading to sleep initiation in relation to phase of entrainment. Sleep Medicine Reviews $2007 \mathbf{1 1}$ 439-451. (doi:10.1016/j.smrv.2007.07.001)

23 Pevet P \& Challet E. Melatonin: both master clock output and internal time-giver in the circadian clocks network. Journal of Physiology 2011 105 170-182.

24 Krauchi K, Cajochen C, Pache M, Flammer J \& Wirz-Justice A. Thermoregulatory effects of melatonin in relation to sleepiness. Chronobiology International 200623 475-484. (doi:10.1080/ 07420520500545854)

25 Schwartz WJ, Busis NA \& Hedley-Whyte ET. A discrete lesion of ventral hypothalamus and optic chiasm that disturbed the daily temperature rhythm. Journal of Neurology 1986233 1-4. (doi:10.1007/ BF00313981)

26 Cohen RA \& Albers HE. Disruption of human circadian and cognitive regulation following a discrete hypothalamic lesion: a case study. Neurology 199141 726-729. (doi:10.1212/WNL.41.5.726)

27 Fronczek R, Overeem S, Lammers GJ, van Dijk JG \& Van Someren EJ. Altered skin-temperature regulation in narcolepsy relates to sleep propensity. Sleep 200629 1444-1449.

28 Raymann RJ, Swaab DF \& Van Someren EJ. Cutaneous warming promotes sleep onset. American Journal of Physiology. Regulatory, Integrative and Comparative Physiology 2005288 R1589-R1597. (doi:10.1152/ajpregu.00492.2004)

29 Raymann RJ, Swaab DF \& Van Someren EJ. Skin deep: enhanced sleep depth by cutaneous temperature manipulation. Brain $2008 \mathbf{1 3 1}$ 500-513. (doi:10.1093/brain/awm315)

30 Biaggioni I. Circadian clocks, autonomic rhythms, and blood pressure dipping. Hypertension 200852 797-798. (doi:10.1161/HYPERTENSIONAHA.108.117234)

31 Scheer FA, Ter Horst GJ, Van der Vliet J \& Buijs RM. Physiological and anatomic evidence for regulation of the heart by suprachiasmatic nucleus in rats. American Journal of Physiology. Heart and Circulatory Physiology 2001280 H1391-H1399.

32 Witte K, Schnecko A, Buijs RM, Van der Vliet J, Scalbert E, Delagrange P, Guardiola-Lemaitre B \& Lemmer B. Effects of SCN lesions on circadian blood pressure rhythm in normotensive and transgenic hypertensive rats. Chronobiology International 199815 135-145. (doi:10.3109/ 07420529808998678)

33 Grossman E, Laudon M \& Zisapel N. Effect of melatonin on nocturnal blood pressure: meta-analysis of randomized controlled trials. Vascular Health and Risk Management 20117 577-584.

34 Krauchi K, Gompper B, Hauenstein D, Flammer J, Pfluger M, Studerus E, Schotzau A \& Orgul S. Diurnal blood pressure variations are associated with changes in distal-proximal skin temperature gradient.
Chronobiology International 201229 1273-1283. (doi:10.3109/ 07420528.2012.719961)

35 Smolensky MH, Hermida RC, Castriotta RJ \& Portaluppi F. Role of sleep-wake cycle on blood pressure circadian rhythms and hypertension. Sleep Medicine 20078 668-680. (doi:10.1016/j.sleep.2006.11.011)

36 Sheward WJ, Naylor E, Knowles-Barley S, Armstrong JD, Brooker GA, Seckl JR, Turek FW, Holmes MC, Zee PC \& Harmar AJ. Circadian control of mouse heart rate and blood pressure by the suprachiasmatic nuclei: behavioral effects are more significant than direct outputs. PLOS ONE 20105 e9783. (doi:10.1371/journal.pone.0009783)

37 Stein PK \& Pu Y. Heart rate variability, sleep and sleep disorders. Sleep Medicine Reviews 201216 47-66. (doi:10.1016/j.smrv.2011.02.005)

38 Ewing DJ, Neilson JM, Shapiro CM, Stewart JA \& Reid W. Twenty four hour heart rate variability: effects of posture, sleep, and time of day in healthy controls and comparison with bedside tests of autonomic function in diabetic patients. British Heart Journal 199165 239-244. (doi:10.1136/hrt.65.5.239)

39 Coomans CP, van den Berg SA, Lucassen EA, Houben T, Pronk AC, van der Spek RD, Kalsbeek A, Biermasz NR, Willems van Dijk K, Romijn JA et al. The suprachiasmatic nucleus controls circadian energy metabolism and hepatic insulin sensitivity. Diabetes 201362 1102-1108. (doi:10.2337/db12-0507)

40 Lipton J, Megerian JT, Kothare SV, Cho YJ, Shanahan T, Chart H, Ferber R, Adler-Golden L, Cohen LE, Czeisler CA et al. Melatonin deficiency and disrupted circadian rhythms in pediatric survivors of craniopharyngioma. Neurology 200973 323-325. (doi:10.1212/WNL. Ob013e3181af78a5)

41 Borgers AJ, Romeijn N, Van Someren EJ, Fliers E, Alkemade A \& Bisschop PH. Compression of the optic chiasm is associated with permanent shorter sleep duration in patients with pituitary insufficiency. Clinical Endocrinology 201175 347-353. (doi:10.1111/j.13652265.2011.04053.x)

42 Van Someren EJ, Swart-Heikens J, Endert E, Bisschop PH, Swaab DF, Bakker PJ, Romijn JA \& Fliers E. Long-term effects of cranial irradiation for childhood malignancy on sleep in adulthood. European Journal of Endocrinology 2004150 503-510. (doi:10.1530/eje.0.1500503)

43 Moller-Levet CS, Archer SN, Bucca G, Laing EE, Slak A, Kabiljo R, Lo JC, Santhi N, von SM, Smith CP et al. Effects of insufficient sleep on circadian rhythmicity and expression amplitude of the human blood transcriptome. PNAS 2013110 E1132-E1141. (doi:10.1073/pnas. 1217154110

44 Manber R, Bootzin RR, Acebo C \& Carskadon MA. The effects of regularizing sleep-wake schedules on daytime sleepiness. Sleep 199619 432-441.

45 Baker FC, Mitchell D \& Driver HS. Oral contraceptives alter sleep and raise body temperature in young women. Pflügers Archiv 2001442 729-737. (doi:10.1007/s004240100582)

46 Soszynski P, Stowinska-Srzednicka J, Kasperlik-Zatuska A \& Zgliczynski S. Decreased melatonin concentration in Cushing's syndrome. Hormone and Metabolic Research 198921 673-674. (doi:10.1055/s-2007-1009317)

47 Lissoni P, Mainini E, Rovelli F, Mazzi C, Ardizzoia A, Gelosa M, Capra M \& Rivolta MR. A clinical study of the pineal hormone melatonin in patients with growth hormone or prolactin secreting pituitary tumours. European Journal of Medicine 19921 407-410.

48 Terzolo M, Piovesan A, Ali A, Codegone A, Pia A, Reimondo G, Torta M, Paccotti P, Borretta G \& Angeli A. Circadian profile of serum melatonin in patients with Cushing's syndrome or acromegaly. Journal of Endocrinological Investigation 199518 17-24. (doi:10.1007/BF03349691)

49 Zwirska-Korczala K, Ostrowska Z, Kos-Kudla B, Buntner B \& Zych F. The lack of melatonin rhythm in active acromegaly after radiotherapy. Endocrine Regulations 199428 97-103.

50 Sinisi AA, Pasquali D, D'Apuzzo A, Esposito D, Venditto T, Criscuolo T, De Bellis A \& Bellastella A. Twenty-four hour melatonin pattern in acromegaly: effect of acute octreotide administration. Journal of 
Endocrinological Investigation 199720 128-133. (doi:10.1007/ BF03346890)

51 Muller HL, Handwerker G, Gebhardt U, Faldum A, Emser A, Kolb R \& Sorensen N. Melatonin treatment in obese patients with childhood craniopharyngioma and increased daytime sleepiness. Cancer Causes \& Control 200617 583-589. (doi:10.1007/s10552-005-9012-7)

52 Karasek M, Stawerska R, Smyczynska J \& Lewinski A. Increased melatonin concentrations in children with growth hormone deficiency. Journal of Pineal Research 200742 119-124. (doi:10.1111/j.1600079X.2006.00388.x)

53 Tomova A, Kumanov P, Robeva R, Manchev S \& Konakchieva R. Melatonin secretion and non-specific immune responses are differentially expressed in corticotropin-dependent and corticotropinindependent Cushing's syndrome. Medical Science Monitor 200814 CR327-CR332.

54 Clar HE. Disturbances of the hypothalamic thermoregulation. Acta Neurochirurgica 198575 106-112. (doi:10.1007/BF01406330)

55 Behr R, Hildebrandt G, Koca M \& Bruck K. Modifications of thermoregulation in patients with suprasellar pituitary adenomas. Brain 1991114 697-708. (doi:10.1093/brain/114.2.697)

56 Juul A, Behrenscheer A, Tims T, Nielsen B, Halkjaer-Kristensen J \& Skakkebaek NE. Impaired thermoregulation in adults with growth hormone deficiency during heat exposure and exercise. Clinical Endocrinology 199338 237-244. (doi:10.1111/j.1365-2265.1993. tb01001.x)

57 Romeijn N, Borgers AJ, Fliers E, Alkemade A, Bisschop PH \& Van Someren EJ. Medical history of optic chiasm compression in patients with pituitary insufficiency affects skin temperature and its relation to sleep. Chronobiology International 201229 1098-1108. (doi:10.3109/ 07420528.2012.708000)

58 Imai Y, Abe K, Sasaki S, Minami N, Nihei M, Munakata M, Murakami O, Matsue K, Sekino H, Miura Y et al. Altered circadian blood pressure rhythm in patients with Cushing's syndrome. Hypertension 198812 11-19. (doi:10.1161/01.HYP.12.1.11)

59 Piovesan A, Panarelli M, Terzolo M, Osella G, Matrella C, Paccotti P \& Angeli A. 24-hour profiles of blood pressure and heart rate in Cushing's syndrome: relationship between cortisol and cardiovascular rhythmicities. Chronobiology International 19907 263-265. (doi:10. 3109/07420529009056985)

60 Matsumura K, Abe I, Fukuhara M, Fujii K, Ohya Y, Okamura K \& Fujishima M. Modulation of circadian rhythm of blood pressure by cortisol in patients with hypopituitarism. Clinical and Experimental Hypertension 199416 55-66. (doi:10.3109/10641969409068584)

61 Fallo F, Barzon L, Boscaro M, Casiglia E \& Sonino N. Effect of octreotide on 24-h blood pressure profile in acromegaly. American Journal of Hypertension 199811 591-596. (doi:10.1016/S0895-7061(98)00029-6)

62 Terzolo M, Matrella C, Boccuzzi A, Luceri S, Borriero M, Reimondo G, Pia A, Rovero E, Paccotti P \& Angeli A. Twenty-four hour profile of blood pressure in patients with acromegaly. Correlation with demographic, clinical and hormonal features. Journal of Endocrinological Investigation 199922 48-54. (doi:10.1007/BF03345478)

63 Ahmad AM, Hopkins MT, Weston PJ, Fraser WD \& Vora JP. Effects of GH replacement on 24-h ambulatory blood pressure and its circadian rhythm in adult GH deficiency. Clinical Endocrinology 200256 431-437. (doi:10.1046/j.1365-2265.2002.01491.x)

64 Conceicao FL, de Rooij Mansur VA, Brasil RR \& Vaisman M. Ambulatory monitoring of blood pressure in growth hormone-deficient adults. Blood Pressure Monitoring 20027 89-94. (doi:10.1097/00126097200204000-00001)

65 Zacharieva S, Orbetzova M, Stoynev A, Shigarminova R, Yaneva M, Kalinov K, Nachev E \& Elenkova A. Circadian blood pressure profile in patients with Cushing's syndrome before and after treatment. Journal of Endocrinological Investigation 200427 924-930. (doi:10.1007/ BF03347534)

66 Krzyzanowska K, Schnack C, Mittermayer F, Kopp HP, Hofer M, Kann T $\&$ Schernthaner G. High prevalence of abnormal circadian blood pressure regulation and impaired glucose tolerance in adults with hypopituitarism. Experimental and Clinical Endocrinology \& Diabetes 2005113 430-434. (doi:10.1055/s-2005-865772)

67 Fallo F, Maffei P, Dalla PA, Carli M, Della MP, Lupia M, Rabbia F \& Sonino N. Cardiovascular autonomic function in Cushing's syndrome. Journal of Endocrinological Investigation 200932 41-45. (doi:10.1007/ BF03345677)

Received 28 February 2014

Revised version received 7 May 2014

Accepted 14 May 2014 